\title{
COMMUNITY EFFICACY AND SOCIAL CAPITAL: MODELLING HOW COMMUNITIES DELIVER OUTCOMES FOR MEMBERS
}

\author{
Sue Kilpatrick and Joan Abbott-Chapman, University of Tasmania, Australia
}

\begin{abstract}
In this analytical paper we introduce a new way of thinking about the social capital of a community, linked to the community's capacity to deliver favourable outcomes for its members. This capacity is termed community efficacy. The paper reports on the initial stages of a project that is building the knowledge base and developing a framework for measurement of outcomes that accrue to rural communities. We focus on aspects of health service provision as exemplars of what our model and measurement framework may be used to achieve, illustrated by two case study communities in Tasmania, Australia.
\end{abstract}

We present a model for the study of community efficacy which illustrates the link between community activity infrastructure and community efficacy and between the structural and dynamic elements of community transactions which go to make up the concept of social capital. This paves the way for a measurement framework against which a community's efficacy and the wellbeing outcomes of its members may be rated within any nominated social domain, and the robustness of its social capital may be assessed. The framework recognises that social capital resources are used at the point of interaction between community members; hence at a practical level opportunities for interaction are important. It also advances theoretical understanding of social capital and how it works in communities.

While the literature suggests that the quality and quantity of a community's social capital has a large impact on that community's capacity to deliver favourable outcomes for its members and its capacity to manage its own future, social capital remains notoriously difficult to measure despite many attempts to do so. There is consensus that social capital is the 'property' of a community or collective, yet in measurement frameworks social capital is normally aggregated across individuals and different levels. Our model attempts to disaggregate and to tease out the different strands and dimensions involved in the 4 domains of Education, Employment, Health \& Welfare, and Voluntary Social Groups. We argue that, as communities are not so socio-economically homogenous, the differential capacity of various groups within the community to participate, and their differential access to decision making structures, should be included. Further, social capital must be set in context - social capital resources that are effective in one context are not necessarily effective in another. We suggest that the framework can be applied to measure community efficacy in various settings, and discuss how it can be applied to a rural community's ability to foster good health and general community 'wellbeing' outcomes at the planning and practical levels. 


\section{COMMUNITY EFFICACY AND SOCIAL CAPITAL: MODELLING HOW COMMUNITIES DELIVER OUTCOMES FOR MEMBERS}

\section{Sue Kilpatrick and Joan Abbott-Chapman, University of Tasmania, Australia \\ BACKGROUND TO THE RESEARCH: DIFFICULTIES IN MEASURING THE IMPACT OF COMMUNITY SOCIAL CAPITAL ON WELL-BEING OUTCOMES}

For over half a century, since the pioneering Peckham Experiment in central London (Pearse \& Crocker 1943), there has been a growing body of evidence linking a community's social sufficiency, self-help and social cohesion with improved mental and physical health and general 'well-being' outcomes of its members (Eckersley 1998). However, despite countless studies over the years, establishing causal links between community social capital and community members' well being outcomes has proved exceedingly difficult. For example, recent reports from the UK have shown the impact of positive social interactions and social support on young people's mental health and wellbeing (Edwards 2003), but, at the level of area level data, findings on the contribution of social capital indicators to defined health outcomes are inconclusive (Mohan, Bernard, Jones \& Twigg 2004). Social capital, what it is and what it does, are notoriously difficult to measure (National Statistics 2001, Productivity Commission 2003) but the policy imperatives for finding measured evidence of such a link, as the key to community capacity building, are increasing. The $\operatorname{OECD}(1999,2001)$ and National Statistics (2001), all note the link between socio-economic outcomes and social capital. Policymakers are looking to research to establish 'what works' in terms of social policy interventions, and social, education and health service delivery; how to intervene in communities effectively and how to work with communities through community participation and community capacity building (Reddel 2002). We contend that the way in which these elements interact within any community may be modelled within a multi-dimensional framework containing standardised 'elements' in such a way that the 'strong' and 'weak' points in the structure may be identified. A 'diagnostic tool', which brings together research capacity and local knowledge of community residents, will assist community members and policy makers alike in identifying points at which timely intervention will achieve desired community goals (Kilpatrick, Abbott-Chapman, Williamson \& Bound 2003, Kilpatrick \& AbbottChapman 2005). In this paper we present work in progress on our model of Community Efficacy and associated Measurement Matrix as applied to health and wellbeing outcomes data in two small rural communities in Tasmania, Australia. In this context community social capital represents processes of social interaction producing particular community outcomes, rather than as an outcome in itself, and hopefully clarifies some current confusion on this point (Fenton, Macgregor \& Cary 2002:118).

The development of our interactive model of Community Efficacy grew out of our attempts, through a series of Australian rural community studies, to address those problems or weaknesses that we see as inherent in much of the body of work on Social Capital over recent years. These are in brief variations in definition and application of the concept of Social Capital in different social contexts; difficulties in identifying and measuring community inputs and outputs along a range of well-being dimensions; inadequate attention to the contribution made by community institutions to community social capital; shortcomings in identifying the weak as well as strong points in the structure of social capital; underestimation of the unequal distribution of access to community social capital and lack of attention to community inequalities and power structures; and inability to satisfactorily meld 'local knowledge' with 'research expertise'. Just a few comments in elaboration will explain what we mean. In a World Bank publication (Woolcock \& Narayan 2000), and the OECD's examination of the relationship between human and social capital (2001), social capital has been defined as the shared information, norms, values and social networks that enable people to work together to achieve beneficial outcomes for the collective. These and other international studies reveal that there are many different definitions of social capital which may vary across case studies, but that most recognise the importance of positive social networks, trust and mutual support (all in themselves however presenting problems of measurement and cultural variation). Despite many attempts to do so, it is widely recognised that social capital is notoriously difficult to measure in relation to a range of economic, social and wellbeing dimensions (ABS 2001, 2002). The Australian Bureau of Statistic's social capital framework (ABS 2004a) conceives social capital as the aggregation of individuals' outcomes and perceptions. This approach undervalues the contribution of community institutions to community social capital, and so to outcomes for individual members. The challenge is to unravel the impact of elements which make up the community infrastructure and those which make up community resilience, belonging and solidarity as they interact together to produce development or decline. 
Since communities are not socially homogenous and some groups have manifestly more social and/or economic power than others, the nature and quality of opportunities are unequal. Community 'can look very different depending on where one is sitting' (Walter 1997:72). Therefore, the differential capacity of various groups within the community to access opportunities, information and social networks and participate (Herbert-Cheshire 2003) must also be fully factored into the social capital equation. Models and measures of community social capital must take into account the diversity of the community, its subgroups and subcultures and the potentially unequal access of groups and individuals to the available community social capital. Our own research suggests that it is highly possible that 'community' social capital may exclude some groups. This is the dark side of social capital referred to by Putnam (2000). Groups excluded from aspects of community social capital are likely to be excluded from related social and economic wellbeing. Models need to be able to identify this and usually cannot. In addition, research has shown that provision by government of facilities and services within a community, such as health services and educational institutions, will not ensure take up, effective utilisation and community benefit. The quality of local leadership, and patterns of governance, have a large impact on each community's capacity to take up social and economic opportunities and to manage change (Gittell \& Vidal 1998, Falk \& Kilpatrick 2000, National Statistics 2001).Thus the degree of social impact and community outcomes will vary from community to community, even with similar infrastructure.

\section{DEVELOPING THE MODEL OF COMMUNITY EFFICACY}

Key questions raised by the above studies centre upon the need to model and measure, in more precise ways than we have been able to do previously, the complex interactions and impact of community factors, including social capital, which are able to produce and to reproduce beneficial outcomes for various community groups. There is also a need to represent the structural and dynamic features which make-up community sustainability. Consequently, our Model of Community Efficacy was developed to address these issues and draws on our own work in Australia along with other international work on social capital in small rural communities. Our model includes within it a community's social capital as a dimension embracing various named components or elements which are valued by community members. This dimension interacts in our model with the dimension of 'Community Activity Infrastructure' which also includes a number of named elements (Kilpatrick, Abbott-Chapman, Williamson \& Bound 2003, Kilpatrick \& Abbott-Chapman 2005).

The concept of 'Community Activity Infrastructure' is a novel addition to thinking about community social capital. This includes the framework of institutional facilities, services and socio-economic resources as applied to specific behaviour settings (Wicker 1991), available at different levels in each community, which facilitate and help to shape the social capital interactions and relationships of its members. This concept embeds Giddens' theory of 'structuration'; of structure as 'both enabling and constraining'; and the 'mutual dependence of structure and agency' (Giddens 1990:69) in seeking to explain the relationships between systems, structures and the interactions of individual actors, in particular communities. The Community Activity Infrastructure sets boundaries to, or acts to enable, the development of community capacity, well-being and social capital, through what we have called Community Efficacy. This concept modifies and applies Bandura's famous concept of individual agency or efficacy (Bandura 1977, 1982) at the level of community. Our model of Community Efficacy enables the efficacy of institutions (formal and informal) to be assessed as part of the whole.

Community efficacy is built through participation in common activities, shared understandings and values, extensive networks (internal and external), previous successful experience of working together where perseverance has been exercised, (failures undermine efficacy), internal and external partnerships between government and non-government organisations and long-term aims that overlap the goals of the diverse groups involved. Community efficacy reflects levels of social trust in civic institutions (Misztal 1996). Our model allows us to discover community members' own sense of what is good about their own community and what shapes their aspirations for themselves and their children (Abbott-Chapman \& Kilpatrick 2001, Kilpatrick \& Abbott-Chapman 2002). The Model of Community Efficacy is best applied in operation as a measurement matrix. We know of only one other recent approach to the measurement of social capital which has similar features to ours in its use of an interactive model, but the elements and interrelationships are quite different as are the modes of measurement (Cheers 2005). 


\section{APPLYING THE COMMUNITY EFFICACY MEASUREMENT MATRIX}

The Community Efficacy measurement matrix relates the structural aspects of Community Activity Infrastructure along one axis and the quantifiable and qualitative elements of social capital along the other. The first dimension encompasses the facilities, services and resources which are available, or the structure of opportunities. It includes the government, community and commercial institutions in the community, the physical and socio-economic resources which provide opportunities for activity choice, interaction and the framing of life chances. The second dimension covers participation, access, diversity, leadership and internal/external orientation which make up community social capital. Community Efficacy is the product of each element along one dimension interacting with each element on the other dimension 'Raw' data in each matrix 'cell' can subsequently scored so that the level of community efficacy overall may be quantified. The Measurement Matrix is shown in Figure 1.

Figure 1: Measuring community efficacy - structure and agency

\begin{tabular}{|c|c|c|c|c|c|c|c|c|c|}
\hline \multirow{2}{*}{\multicolumn{2}{|c|}{$\begin{array}{l}\text { Community Activity Infrastructure } \\
\text { - Structure of Opportunities }\end{array}$}} & \multicolumn{2}{|c|}{$\begin{array}{l}\text { Structure } \\
\text { Access } \\
\text { and } \\
\text { Change }\end{array}$} & \multicolumn{6}{|c|}{$\begin{array}{l}\text { Quality of Community Social } \\
\text { Capital }\end{array}$} \\
\hline & & \multirow{2}{*}{ 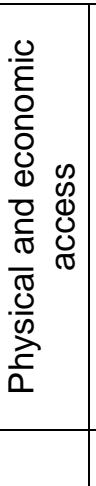 } & \multirow{2}{*}{ 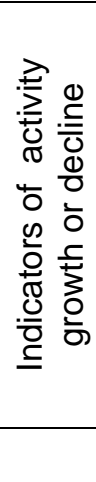 } & \multirow{2}{*}{ 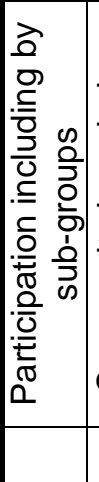 } & \multirow{2}{*}{ 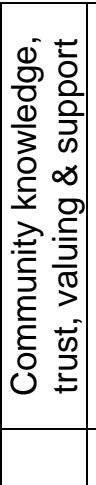 } & \multirow{2}{*}{ 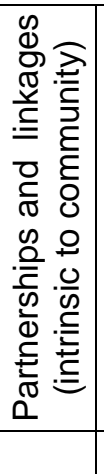 } & \multirow{2}{*}{ 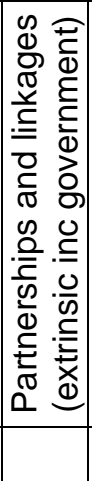 } & \multirow{2}{*}{ 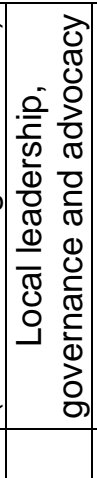 } & 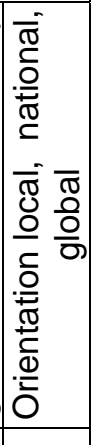 \\
\hline \multirow{3}{*}{ 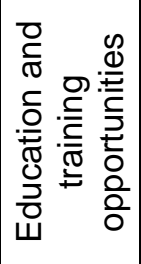 } & Schools & & & & & & & & \\
\hline & Post-school education and training & & & & & & & & \\
\hline & $\begin{array}{l}\text { Structured and informal learning } \\
\text { opportunities outside the formal } \\
\text { education and training sector }\end{array}$ & & & & & & & & \\
\hline \multirow{3}{*}{ 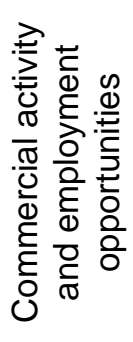 } & $\begin{array}{l}\text { Employers (businesses, government \& } \\
\text { community services and industries) }\end{array}$ & & & & & & & & \\
\hline & $\begin{array}{l}\text { Job agencies and employment services } \\
\text { (government \& NGOs) }\end{array}$ & & & & & & & & \\
\hline & $\begin{array}{l}\text { Commercial community services, e.g. } \\
\text { banks, post office, shops retail and } \\
\text { wholesale, cafes, tourist enterprises }\end{array}$ & & & & & & & & \\
\hline \multirow{3}{*}{ 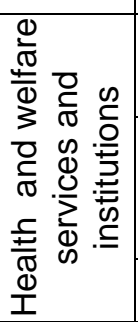 } & $\begin{array}{l}\text { Medical health services (physical and } \\
\text { mental) }\end{array}$ & & & & & & & & \\
\hline & $\begin{array}{l}\text { Community health, welfare and support } \\
\text { services and programs, govt and not- } \\
\text { for-profit (including aged care) }\end{array}$ & & & & & & & & \\
\hline & Allied health services & & & & & & & & \\
\hline \multirow{3}{*}{ 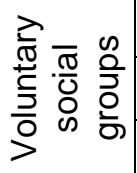 } & Social, arts, cultural \& sports clubs & & & & & & & & \\
\hline & Civic, political, business associations & & & & & & & & \\
\hline & Religious/spiritual groups, churches & & & & & & & & \\
\hline
\end{tabular}


Indicators are being developed for each cell of the quality of social capital columns in the measurement matrix. These will be drawn from suites of quality performance and benchmarking measures where ever possible. In the health section, for example, the Tasmanian government, through the Tasmania Together initiative, has identified the need for a range of health and well-being benchmarks (www.tasmaniatogether.gov.au). The Quality Improvement Council's suite of quality of performance indicators for health institutions include areas such as community participation (www.qic.org.au).

Once the primary and secondary data for each element have been evaluated they are given a score. The final score in each cell in the matrix summates the community activity infrastructure score multiplied by the quality of social capital score. This is a complex process which we are working to refine. We are in the early stages of primary and secondary data collection in two Tasmanian communities with the aim of identifying, and measuring, elements in the matrix which are most closely associated with health and wellbeing outcomes. The first stage in the process was the identification of measured health and wellbeing outcomes which might be expected to be affected by the relative strength of a community's 'efficacy'. Key indicators or outcomes of health and well being within Tasmania were identified using the national health data library (Department of Health and Ageing 2004). After examination of the literature, nine key indices, which have recognised social correlates, were selected and the rates of incidence were plotted for every statistical area in the whole of Tasmania (population 484,000). These indices are: Injuries, poisonings and violent deaths; Accidents, excluding motor vehicle traffic hospital separations; Accidents motor vehicle traffic hospital separations; Motor vehicle transport accident deaths; Attempted suicide or self-inflicted injuries and poisoning hospital separations; Intentional self harm deaths; Diabetes mellitus deaths; Ischaemic heart disease deaths; Cerebrovascular disease - stroke deaths. The rates for each of these indices were then scored 1 to 8 where 1 is 'low' and 8 is 'high' (where low represents a relatively good outcome for community members and high represents a relatively poor outcome for community members). These became the indicative health and wellbeing outcomes we are seeking to relate to community efficacy.

We hypothesised that if two geographically bounded rural communities of similar size, socio-economic status and access to the nearest regional centre could be found which have widely different health outcomes against these measured indices, then by applying our measurement matrix we are able to investigate any differences in activity infrastructure and social capital which might help to explain these differences. This paper shows how we went about this, and indicates some very early findings.

\section{HEALTH AND WELFARE DATA IN THE CASE STUDY TOWNS}

Tasmania has been chosen as the starting point for our investigations for two main reasons. Firstly, Tasmania has some of the worst socio-economic, education and health indices of the nation (Glover, Harris \& Tennant 1999, ABS 2004b) so that finding social 'triggers' for health and wellbeing is an urgent practical necessity. Secondly, Tasmania has a very active University Department of Rural Health which is building partnerships in local communities and has set up Rural Health Teaching sites, whose key result areas include development of innovative health service delivery and rural community engagement at many levels. Local community collaborations and partnerships are likely to ensure the success of 'bottom up' community consultations which are planned. What we discover in the rural communities of Tasmania will form useful models for similar communities throughout Australia, and hopefully in other parts of the world.

The 26 Tasmanian statistical local areas were ranked in terms of their overall scores on all our health indices. A number of possible case study communities were selected which ranked low or high on the Indices. These possible choices were then compared for size, access and socio-demographic characteristics, using a modified version of the model of Educational Handicap (Abbott-Chapman, Hughes \& Wyld 1991). The two communities chosen, called A (better health outcomes) and B (poorer health outcomes) to preserve anonymity, are of similar size (around 6,000 inhabitants), and are local government area bounded communities about an hour's drive from the nearest regional centre. Despite some differences in dominant industry, with Community A's economy largely based on agricultural and pastoral activities and Community $B$ relying heavily on industrial activities, they are closely comparable on a range of socio-demographic indices (ABS 2001b). These include median age (p.61), median personal weekly income (p.59), age pensions per thousand, youth allowance per thousand (p.61), unemployment allowance per thousand (p.61), number of car licences (p.109), and 
home ownership (p.120). Having matched the two communities on key indicators we feel confident to look for evidence of community efficacy differences which might explain the differences in specified community health outcomes. Community A ranked 1 or 2 on five of the nine indices, and 7 or 8 on none, while Community B ranked 7 or 8 on six indices, and 1 or 2 on only one (injuries, poisonings and violent deaths).

In the first stages of 'raw' data gathering (prior to scoring and scaling) we have focussed on the matrix 'health and welfare' sections, and intend to cover all other sections as the research progresses. Firstly programs and institutions were identified in the two communities from the Internet and publicly available documents. We then examined evidence available from secondary sources that related to the elements in the quality of social capital columns of the matrix which might produce positive health and wellbeing outcomes for community members. This evidence included detailed local government documents. We found not only evidence about physical and economic access, but also evidence of growth, partnerships between services and institutions within and outside the communities and local leadership, governance and advocacy. It was inevitable that a number of institutions or services would also be represented in other sectors of Community Activity Infrastructure, such as church run welfare groups. We noted that multidimensional representation of particular institutions or programs is an expected feature of the matrix and is consistent with the flexible nature of the model.

\section{DISCUSSION OF PRELIMINARY FINDINGS AND ISSUES TO BE ADDRESSED}

A number of similarities between the communities have emerged with regard to 'community activity infrastructure' of health and welfare services. Both communities have access to a range of medical, allied health and community health and welfare services. Both have developed linkages and partnerships between local organisations and with external organisations. Links with the nearest major population centre are another key feature of both communities, particularly in providing allied health services on a visiting basis and by subsidised transport for access to health services not available locally. Community A has a community care centre that provides residential care, community care, primary health services, community housing and transport. Community B has a well developed health care infrastructure including a hospital, council run community services and an aged care facility.

There are however some key differences between Community A and B in terms of local leadership and governance. These seem to underline the importance of pro-active local leadership and public participation in identifying and meeting local needs, rather than a more compliant community response to services provided by government. Community B relies heavily on state and local government funded community services, which are largely organised by the local council or through the state government run hospital. Community A, in contrast, has shown remarkable local leadership and advocacy through forming a group of concerned health professionals and local community members to address previous significant gaps in the provision of health services in the community. This group lobbied the Australian Government Department of Health and Ageing to provide funding to support a new range of services in the community. Despite initial scepticism from the local community, the group developed a significant partnership with a local aged care facility, which has resulted in the establishment of a Community Health Centre providing over 14 new medical, allied health and community services to the region. This leadership and advocacy inspired the local community and many of these services are now provided by local private practitioners. The community health committee considered local needs and worked to meet them, in spite of a lack of leadership from local government. For example, it identified a need for mental health services, a need common to most Tasmanian rural communities. It arranged a link to an interstate 24 hour support service, resulting in a service that is more extensive than that available in other Tasmanian communities, including Community B. We intend to interview leaders in both communities and to conduct surveys to evaluate local response to changes taking place.

Published documentary and data analysis so far suggest a difference in social capital between these two communities, and in 'use' of activity infrastructure, which qualitative surveys will need to investigate. While Community $B$ is well organised and has an established health infrastructure, the local community seem mainly consumers of services without being instrumental in identifying and meeting needs in the community. Conversely, Community A has responded to a perceived lack of leadership in the local Council by rallying the local community and the Australian Government to effect considerable change in their community. The outcome is health and welfare services that appear to have become more closely aligned with identified community needs over time. It is too early to say how this will translate into the measurements within our matrix but findings are suggestive. 
We acknowledge the difficulty in proving causal links between community efficacy and health and wellbeing outcomes, and the demonstration of such links may be a long way ahead. There is also the question of the direction of causation: does Community $\mathrm{A}$ have better health outcomes because it has higher quality of social capital? Is the more established health infrastructure in Community B there because Community $B$ has poor health outcomes that need to be addressed? However, this raises the question of why Community B continues to have poorer health outcomes, despite its long established services. The conclusions we reach here are tentative. The purpose of this paper is to demonstrate the way in which our matrix can be used and developed as a 'diagnostic' tool in examination of complex data to highlight some of these possible connections. We anticipate that as our data gathering progresses, to include questions from established quality performance measures and perception tools, our matrix will help us to identify specific elements within the case study communities which strengthen or weaken community efficacy in influencing particular outcomes for their members.

\section{REFERENCES}

Abbott-Chapman, J., Hughes, P. \& Wyld, C. (1991) Improving Access of Disadvantaged Youth to Higher Education, Evaluations and Investigations Program, Higher Education Division, Commonwealth Department of Employment, Education and Training, Canberra, Australian Government Printing Service.

Abbott-Chapman, J. \& Kilpatrick, S (2001) 'Improving Post-school Outcomes for Rural School Leavers', Australian Journal of Education, 45, 1, 35-47.

ABS (2001a) Measuring Wellbeing: Framework for Australian Social Statistics, Canberra, Australian Bureau of Statistics

ABS (2001b) Regional Statistics: Tasmania Catalogue no. 1362.6, Canberra, Australian Bureau of Statistics.

ABS (2002) Measuring a Knowledge-based Economy and Society: An Australian Framework, Canberra, Australian Bureau of Statistics.

ABS (2004a) Measuring Social Capital: An Australian Framework and Indicators, Canberra, Australian Bureau of Statistics.

ABS (2004b) Australian Social Trends, Canberra, Australian Bureau of Statistics.

Bandura, A (1977) 'Self-efficacy: Toward a Unifying Theory of Behavioural Change', Psychological Review, 84, 191-215.

Bandara, A (1982) 'Self-efficacy Mechanism in Human Agency', American Psychologist. 37, 122-149. Cheers, B., Cock, G., Kruger, M., McClure, L. \& Trigg, H. (2005) 'Measuring Community Capacity: An electronic audit template', Proceedings $2^{\text {nd }}$ National Conference on the Future of Australia's Country Towns, 11-13 July, La Trobe University, Bendigo, Victoria.

Department of Health and Ageing (2004) HealthWiz. Canberra.

Eckersley, R. (1998) Measuring Progress: Is Life Getting Better? Collingwood, Victoria, CSIRO Publishing.

Edwards, L. (2003) Promoting Young People's Wellbeing: A Review of Research on Emotional Health. S.C.R.E. Centre, University of Glasgow Research Report 115.

Falk, I. \& Kilpatrick, S. (2000) 'What is Social Capital? A Study of Interaction in a Rural Community', Sociologia Ruralis 40, 1, 87-110.

Fenton, C., MacGregor, C. \& Cary, J. (2000) Framework and Review Capacity and Motivation for Change to Sustainable Management Practices Final Report Theme 6, National Land and Water Resources Audit, Canberra, Bureau of Rural Sciences.

Giddens, A. (1990) Central Problems in Social Theory; Action, Structure and Contradiction in Social Analysis, Berkeley, University of California Press.

Gittell, R. \& Vidal, A. (1998) Community Organizing: Building Social Capital as a Development Strategy, London, Sage Publications.

Glover, J., Harris, K. and Tennant, S. (1999) A Social Health Atlas $2^{\text {nd }}$ Ed. Adelaide: Public Health Information Development Unit.

Herbert-Cheshire, L (2003) 'Translating Policy: Power and Action in Australia's Country Towns', Sociologia Ruralis, 42, 4, 454-473.

Johnston, G. \& Percy-Smith, J. 2003 'In Search of Social Capital', Policy \& Politics, 31, 3, 321-334. Kilpatrick, S. \& Abbott-Chapman, J. (2002) 'Rural Young People's Work/study Priorities and Aspirations: The Influence of Family Social Capital', Australian Educational Researcher 29, 1, 43-68. Kilpatrick, S. \& Abbott-Chapman, J. (2005) 'Community Efficacy and Social Capital', Proceedings $2^{\text {nd }}$ National Conference on the Future of Australia's Country Towns, 11-13 July, La Trobe University, Bendigo, Victoria 
Kilpatrick, S., Abbott-Chapman, J., Williamson, J \& Bound (2003) 'Identifying the Characteristics of Rural Learning Communities' Implications for Rural Development. SPERA $19^{\text {th }}$ International Conference 2003, Conference Proceedings, Society for the Provision of Education in Rural Australia, $29^{\text {th }}$ Sept. $-1^{\text {st }}$ Oct. $83-92$.

Mistzal B. (1996) Trust in Modern Societies, Oxford, Polity Press

Mohan, J., Bernard, S., Jones, K. \& Twigg, L. (2004) Social Capital, Place and Health: Creating Validity and Applying Small Area Indicators in the Modelling of Health Outcomes, NHS Health Development Agency. http://www.hda-online.org.uk/Documents/socialcapital place health.pdf National Statistics (2001) Social Capital: A Review of the Literature, London, Office for National Statistics.

OECD (1999) Social Indicators: A Proposed Framework and Structure. Paris.

OECD (2001) The Well-Being of Nations: The Role of Human and Social Capital, Paris, OECD. Pearse, I. \& Crocker, L. (1943) The Peckham Experiment: A Study of the Living Structure of Society. London, George Allen \& Unwin Ltd.

Productivity Commission (2003) Social Capital: Reviewing the Concept and its Policy Implications. Research Paper, Canberra,Ausinfo.

Putnam, R. (2000) Bowling Alone: The Collapse and Revival of American Community, New York, Simon and Schuster.

Reddel, T (2002) 'Beyond Participation, Hierarchies, Management and Markers: 'New' Governance and Place Policies', Australian Journal of Public Administration 61, 1, 50-63.

Walter, C. (1997) 'Community Building Practice: A Conceptual Framework', in Community Organizing and Community Building for Health, M. Minkler (ed) New Brunswick NJ, Rutgers University Press. Wicker, AW (1991) 'Behaviour Settings Reconsidered: Temporal Stages, Resources, Internal Dynamics, Context', in D Stokols \& I Altman (eds) Handbook of Environmental Psychology, Malabar, FLA; Krriegar Publishing Company, 613-53.

Woolcock, M \& Narayan, D. (2000) Social Capital: Implications for Development Theory, Research and Policy. World Bank Research Observer, 15,2, 225-49. 